\title{
Turismo, Arte e Contextos Periféricos. Considerações em Torno das Artes Plásticas Africanas
}

https://doi.org/10.21814/uminho.ed.48.3

José Carlos Venâncio

Centro de Estudos de Comunicação e Sociedade, Universidade do Minho, Braga, Portugal/ Universidade da Beira Interior, Covilhã, Portugal https://orcid.org/0000-0003-0428-1914

venancio@ubi.pt

\section{Resumo}

Na sequência do crescente peso que a cultura tem vindo a assumir nas economias dos países mais desenvolvidos, a arte contemporânea africana é entendida como um potencial fator de desenvolvimento da indústria do turismo em África e, especificamente, em Moçambique. A comercialização a que a arte está ou passará a estar sujeita não representa, no contexto desta discussão, qualquer perigo de empobrecimento estético, desde que as políticas públicas incentivem, por um lado, a produção artística com os meios e as condições necessárias à garantia de qualidade e, por outro, providenciem informação adequada aos potenciais compradores.

\section{Palavras-chave}

África, Moçambique, arte contemporânea, turismo, periferia

Ao mercantilizar a arte, o capitalismo contribuiu simultaneamente para democratizá-la, até certo ponto. -Will Furtado (2018, p. 46)

O primeiro propósito deste ensaio é o de demonstrar que a arte contemporânea africana pode ser, se não o é já, um importante produto e fator na dinamização do turismo em África e, consequentemente, um importante incentivo ao desenvolvimento das respetivas economias e sociedades. 0 segundo objetivo é o de demonstrar que a comercialização da arte, o equacionamento da componente mercado 
no processo produtivo da arte, não conduz forçosamente a um empobrecimento estético da mesma. Fazer-se "boa arte não é, em si, contraditório com o fazer-se bom ganho financeiro", diz, a esse propósito, Serge Tiroche, co-fundador da Tiroche DeLeon Collection, em entrevista concedida a Tayla Withers (2017, p. 142).

Em conformidade, a reflexão que se segue terá em conta o crescente e reconhecido papel que a cultura, sobretudo após os anos 70 do século passado, vem assumindo, mormente no seio das economias desenvolvidas, contribuindo para o processo de estetização dessas mesmas economias (Reckwitz, 2014) e, consequentemente, para a consolidação das chamadas indústrias culturais. Dar-se-á especial atenção às artes plásticas africanas contemporâneas, cujo reconhecimento internacional tem vindo a acontecer a um ritmo significativo, tornando os seus produtos (produzidos localmente ou na diáspora) interessantes aos olhos de colecionadores, galeristas e demais atores que intervêm nos circuitos internacionais da arte.

Por turismo entende-se o conjunto de atividades que envolvem o deslocamento de pessoas de um lugar para outro, em termos domésticos e internacionais, com um propósito explícito de lazer. 0 turismo é, na verdade, uma atividade tão velha quanto a condição humana. A curiosidade por outras culturas e vivências e, através dela, granjear um estatuto melhorado na sociedade de origem, como a antropologia tem evidenciado a propósito do estudo dos ritos de iniciação, é, pois, uma atividade ou prática que acompanhou as primeiras formas de organização das sociedades. Em termos industriais, começa a ser explorado no século XIX, na senda da industrialização, da mecanização e do ócio que tais processos vieram proporcionar a uma parte da população. $O$ desenvolvimento dos meios de transporte, mormente das linhas férreas, é outro importante fator a contribuir para a sua emergência. No século XIX emergem e afirmam-se muitos dos hábitos que marcam o nosso quotidiano. A prática do turismo é um deles.

Thomas Cook terá sido o primeiro agente de viagens a servir-se desses meios para implementar as primeiras viagens de turismo coletivo. Nos anos 60 do século passado, no encalço do boom económico que então se verificou, o turismo, nos países industrializados, atinge níveis massivos, condição que se vai alargando progressivamente a grande parte do globo até ao nível de desenvolvimento atual.

O turismo é hoje uma indústria de que os países, a começar pelos mais desenvolvidos em termos económicos e sociais, não prescindem, dadas as receitas económicas que a mesma proporciona. A globalização, o enorme crescimento da mobilidade das pessoas, a implementação e o embaratecimento das passagens de avião com a liberalização do mercado dos transportes aéreos têm contribuído fortemente para o seu incremento. A par de benefícios reconhecidos, como qualquer outra atividade económica, o turismo importa igualmente riscos, que não são, de maneira alguma, de menosprezar.

Os riscos em questão têm a ver com desequilíbrios que a deslocação massiva de pessoas, capitais, hábitos e valores podem causar nas sociedades recetoras. Reconhecem-se, a este respeito, consequências a nível ambiental, social, cultural e económico, 
fatores desestruturantes nos seus efeitos, cuja superação tem sido possível com a implementação de estratégias inovadoras que têm conduzido ao desenvolvimento de formas de turismo mais sustentáveis, de que o ecoturismo ou turismo da natureza é devedor. A par deste, outros tipos de turismo, com idênticas preocupações quanto à preservação dos ecossistemas, têm sido implementados, como seja o turismo rural, o turismo da natureza com a componente de aventura, assim como no próprio turismo de caça e pesca que, sendo exercitado sob a vigilância de tais preocupações, pode constituir uma via economicamente sustentável para a preservação de espécies num contexto ecológico que é forçosamente diferente do suposto sistema inicial. 0 turismo cultural, tema central nesta análise, é um dos tipos de turismo que, preservando e dando a conhecer as culturas locais, se enquadra, pela sua própria natureza, no grande chapéu do turismo ecologicamente sustentável.

O turismo, enquanto atividade económica, apresenta ainda algumas outras particularidades. Uma delas é o facto de, diferentemente dos outros sectores da economia, não produzir bens, isto é, dele extraem-se apenas receitas indiretas, relacionadas com a criação de infraestruturas de atração, com instalações de acomodação e, nos últimos anos, com o desenvolvimento acentuado de vias de comunicação, de serviços de acompanhamento (guias turísticos, pessoal da restauração, entre outros) e, em contextos economicamente menos desenvolvidos, com a implementação de estruturas sanitárias e hospitalares.

Muitas destas ações e infraestruturas, implementando o desenvolvimento nas economias e sociedades de receção, acabam por beneficiar, de igual modo, as populações locais, mormente se se adotarem as estratégias adequadas, isto é, políticas públicas capazes de minimizar os efeitos nefastos que a dependência que a atividade turística, exercida muitas vezes como única indústria, gera em tais sociedades e economias.

A situação descrita, os riscos e os benefícios apontados desenham um quadro geral, com uma valência universal, que varia consoante as situações específicas do país ou da região recetores da atividade. As sociedades menos estruturadas, que 0 mesmo será dizer, menos desenvolvidas, estão mais expostas a esses riscos do que as sociedades mais desenvolvidas. São riscos de descaracterização e até de desintegração, envolvendo processos que as respetivas elites, muitas vezes fragilizadas e deslegitimadas, se revelam incapazes, voluntária ou involuntariamente, de contrariar. E, se este quadro é válido para grande parte do que, a dada altura, se convencionou designar por "terceiro mundo", ele é ainda mais evidente nas sociedades e economias da África subsariana.

A indústria do turismo é introduzida na África subsariana pelas administrações coloniais. “Até ao início dos anos 60" - escreve Sindiga (1999) - "o turismo era praticado por algumas pessoas ricas da Europa ocidental e da América do Norte, muitos deles interessados na pesca desportiva, na caça desportiva e nos respetivos troféus", que chegavam aos destinos turísticos de barco (p. 21). Tratava-se, na verdade, de um turismo de aventura que, nos seus propósitos, reproduzia o gosto e as idiossincrasias do século XIX, em muito estigmatizadas pela antinomia civilização versus selvajaria, 
quer fosse esta última designação reportada às populações locais, colonizadas ou em vias de o ser, quer aos animais de grande porte de que o continente era rico. Era, pois, um turismo desenvolvido para deleite do indivíduo branco e, como tal, após as independências, na década de 60 do século passado, a atividade foi refreada ${ }^{1}$ nos países que enveredaram pela via socialista, pelo alinhamento ao bloco socialista, mormente à União Soviética, que, antes da constituição da Organização de Unidade Africana², em 1963, constituíam o grupo de Casablanca.

Diferente foi a postura dos países alinhados com o mundo capitalista, que o mesmo será dizer, com as antigas metrópoles, que formavam o grupo de Monróvia, ao qual pertenceu o Quénia, talvez o exemplo mais paradigmático quanto à continuação da atividade turística em contexto pós-colonial.

Hoje, com o fim da Guerra Fria e dos seus efeitos em África, com a emergência da conjuntura de globalização já referida, a atividade turística tem vindo a ser implementada por todo o continente, conquanto com algumas limitações que já não decorrem propriamente de posicionamentos político-ideológicos, mas sim da ausência de condições de ordem infraestrutural e financeira. Com base nas estatísticas disponíveis, fornecidas por organismos internacionais como o Banco Mundial, a Organização Mundial do Turismo (UNWTO) ou a Conferência das Nações Unidas sobre Comércio e Desenvolvimento (UNCTAD), o continente registou desde a década de 90 do século passado um crescimento significativo no que ao turismo diz respeito. Seguindo um estudo deste último organismo (United Nations Conference on Trade and Development [UNCTAD], 2017, p. 14), foram registadas em 1995, no conjunto dos países africanos, isto é, incluindo os da África do Norte, 24.084 .000 chegadas internacionais, tendo esse número, em 2015, subido para 52.803.000. 0 país com o registo do maior movimento de turistas em 1995 foi o Egito, recebendo 3.317 .000 turistas. Em 2015, por certo devido à instabilidade política, foi ultrapassado por Marrocos, que registou, nesse ano, 10.177 .000 entradas. No que respeita à África subsariana, vem em primeiro lugar a África do Sul, registando, em 2015, o considerável número de 8.904.000 entradas. Moçambique registou, nesse ano, 1.552 .000 entradas, um número que, face aos restantes países subsarianos, se revela significativo.

Os dados referentes a 2018, fornecidos pelo UNWTO, no World Tourism Barometer and Statistical Annex (World Tourism Organization [UNWTO], 2019), dão conta de um crescimento de $7 \%$ em chegadas e dormidas (overnight visitors). Um dado interessante a registar a propósito desta conjuntura de crescimento é o de que uma parte significativa desse crescimento, numa relação de quatro para 10 (UNCTAD, 2017), é de turistas provenientes de países africanos. A Tabela 1, referente ao

1 Mesmo em países que, embora próximos da linha soviética, primaram sempre por uma certa neutralidade, como foi o caso de Cabo Verde durante a vigência do regime de partido único, registouse uma relutância em abrir o país ao turismo por razões (diziam-me) que tinham a ver com os efeitos nefastos, em termos de costumes, que estão sempre apensos à deslocação de turistas.

2 A constituição da Organização de Unidade Africana permitiu a ultrapassagem de alguns dos obstáculos que dividiam o nacionalismo em África e os jovens países africanos, recentemente independentes ou em vias disso. Quanto ao alinhamento político e à divisão condicionada/imposta pela chamada Guerra Fria, não se registou qualquer alteração de princípios, passando a organização a albergar no seu seio ambas as tendências (Venâncio, 2009). Tal não implicou que, dos muitos golpes de Estado de que esses países foram acometidos, não se assistisse à troca do lado do conflito por opção das forças golpistas. 
caso específico de Angola, um país que ainda não está propriamente virado para o turismo, exemplifica, de qualquer modo, essa tendência de crescimento a partir de 2006 com o acréscimo do número de chegadas ${ }^{3}$ de turistas provenientes dos países da Comunidade de Desenvolvimento da África Austral, a cuja organização o país pertence.

\begin{tabular}{lcccccccc}
\multicolumn{1}{c}{ Países } & \multicolumn{7}{c}{ Chegadas por ano } \\
& 2006 & 2007 & 2008 & 2009 & 2010 & 2012 & 2013 & Total \\
África do Sul & 9.468 & 13.328 & 15.476 & 25.803 & 29.217 & 82.021 & 94.177 & 269.670 \\
Moçambique & 830 & 6.227 & 1.400 & 1.550 & 3.089 & 1.720 & 2.311 & 17.127 \\
República & 694 & 1.058 & 1.108 & 890 & 446 & 6.958 & 9.528 & 20.682 \\
Democrática do & & & & & & & & \\
Congo & & & & & & & & \\
Namíbia & 700 & 887 & 1.174 & 1.225 & 3.506 & 54.219 & 73.614 & 135.325 \\
Zimbabwe & 355 & 537 & 573 & 598 & 1.317 & 1.404 & 970 & 5.754 \\
Zâmbia & 434 & 516 & 752 & 601 & 1.313 & 10.976 & 19.575 & 34.167 \\
Tanzânia & 101 & 182 & 191 & 140 & 120 & 380 & 212 & 1.326 \\
Botswana & 125 & 138 & 469 & 130 & 88 & 179 & 100 & 1.229 \\
Ilhas Maurícias & 74 & 89 & 83 & 104 & 43 & 214 & 20 & 627 \\
Malawi & 45 & 38 & 129 & 98 & 96 & 92 & 52 & 550 \\
Swazilândia & 45 & 23 & 120 & 61 & 41 & 58 & 17 & 365 \\
Lesotho & 70 & 13 & 67 & 19 & 20 & 27 & 17 & 233 \\
Seychelles & 3 & 1 & 1 & 9 & 7 & 17 & 0 & 38 \\
Total & 13.124 & 23.037 & 21.543 & 31.228 & 39.303 & 158.265 & 200.593 & 487.093
\end{tabular}

O turismo cultural é um dos tipos de turismo que, embora pouco desenvolvido, é oferecido por alguns países e regiões na África subsariana. A cultura, o património histórico-cultural e natural, constituem, neste tipo de turismo, o principal motivo da deslocação, pelo que a implementação de políticas de definição e de preservação desse mesmo património se impõe como condição prévia.

No período colonial, o património étnico, quer nos seus aspetos materiais, quer nos espirituais, se não foi simplesmente desprezado, também não foi devidamente considerado. Se o preservavam, também o menorizavam ao "museologizá-lo", termo que, no propósito desta argumentação, encontra correspondência no de orientalização, devido a Edward Said. Entenda-se, nestes termos, por museologização ou orientalização da cultura africana pré-colonial a identificação da mesma com o que Leclerc (1972/1973, p. 28) designou por "racionalidades mortas", ou seja, racionalidades condenadas a suprimirem-se na análise etnográfica do século XIX, que tinham como correlato a suposta incapacidade do indivíduo africano de entender e abraçar a modernidade subjacente a essas mesmas análises. 0 indivíduo africano (leia-se negro) ${ }^{4}$

3 Tendo em conta que muitos dos vistos concedidos pela rede consular angolana como vistos de turismo se destinam a outros visitantes que não apenas a turistas, é de prever que os números apresentados pequem por alguma imprecisão.

4 Evidentemente que não foram apenas os negros objeto dessa injustiça. Praticamente todos os povos não caucasianos o foram, conquanto o negro tenha sido, na verdade o menos considerado, o mais

\section{Tabela 1}

Fluxo de turistas a Angola provenientes dos países da Comunidade de Desenvolvimento da África Austral entre 2006 e 2013.

Fonte. Nhulilivali, 2017, p. 83. 
era, então, dado como incapaz de produzir modernidade e, como tal, condenado ao vazio. Restava a sua cultura, a que se designava por "primitiva" (hoje designada por "tradicional"), entendida como sobrevivência de um devir histórico que, na base das ideias iluministas e darwinistas, era suposto ser homogéneo. Modalidades artísticas como a literatura (oral) e as artes plásticas (em madeira, sobretudo) passaram a ser valorizadas por estarem, precisamente, condenadas à extinção. Valorizava-se, concomitantemente, a particularidade de um mundo imagético que não só estava condenado ao desaparecimento, como também era único e parado no tempo. Os objetos de arte consignados a este entendimento, com valência etnográfica e museográfica, passaram a ser procurados por colecionadores, museus e galeristas, sendo, não poucas vezes, objeto de tráfico ilícito.

O colonialismo (moderno) que se seguiu a este momento da descoberta do mundo tradicional africano em nada alterou (se não aprofundou ainda mais) o estigma do indivíduo negro. Se o ensino formal (quase sempre nas línguas da colonização) implementado pelas potências coloniais lhe atribuiu algumas ferramentas em prol da sua dignificação, o certo é que esse ensino foi propositadamente desenhado para que os que dele beneficiassem não atingissem os patamares de reflexão e preparação do que era ministrado aos colonizadores.

Após as independências, o propósito explícito de valorizar este património, arredando muitas vezes o património colonial construído da linha evolutiva e reconstrutiva das identidades nacionais, ficou, na maioria das situações, aquém do desejável. As elites pós-coloniais, por incapacidade própria ou por condicionamento de conjuntura, não lograram, na maioria dos casos, integrar harmoniosamente no Estado moderno, em si decalcado do Estado colonial, as comunidades étnico-linguísticas com os seus valores, vivências e expetativas. Noutros termos: não conseguiram articular o mundo tradicional com o moderno em prol da identidade nacional. Os esforços mais significativos que, de qualquer modo, foram desenvolvidos a esse propósito verificaram-se nos Estados em que se havia seguido a via capitalista no processo de (re) construção nacional. Designações como "socialismo africano", a par de outras, como "negritude", "pan-africanismo" e "renascimento africano", dão nota desse desiderato (Venâncio, 2009, 2014).

Incapacitado de modernidade, o indivíduo africano estaria, assim, também incapacitado de produzir arte moderna. Tal estigma veio a ser contrariado, quer no período colonial, quer no pós-colonial, pela ação de artistas, intelectuais e mecenas europeus (Jahn Janheinz, Ulli Beier, Frank McEwen, Pancho Guedes, entre outros) que, acreditando na potencialidade das culturas africanas tradicionais, diferentemente do que, na verdade, haviam feito os modernistas ${ }^{5}$, incentivaram artistas africanos a

desumanizado. "O Negro representa" - escreve Mbembe (2013/2014) na linha de uma argumentação que já fora desenvolvida por Amílcar Cabral - "representa ( ... ) uma das perturbadoras figuras da nossa modernidade, da qual ele é ( ... ) a parte do mistério e do escândalo" (p. 73).

5 Reconhecendo embora a pujança das formas artísticas africanas, os modernistas e outos pintores europeus acabaram por não reconhecer devidamente o contributo recebido. "Parece que Paul Gauguin, homem bastante distraído" - escreve Eduardo Galeano (2009) - "pôs sua assinatura num par de esculturas do Congo. $\mathrm{O}$ erro foi contagioso. A partir de então, Picasso, Modigliani, Klee, Giacometti, Ernst, Moore e 
produzirem arte moderna, baseados precisamente nas referências das suas culturas de origem. Um desses relacionamentos proveitosos foi o do arquiteto Pancho Guedes com o pintor Malangatana (Chabal, 1994; Costa, 2013; Neves, 2013; Sopa, 2017), levando este último a incorporar nas suas criações a imagética e os demónios da sua cultura de origem. Estabeleceu-se, desta forma, uma ponte entre o que hoje se designa por arte tradicional africana e a contemporânea.

Sendo esta uma das vias da emergência da arte contemporânea africana, outras houve, nomeadamente a que, seguindo o modelo de autonomização das literaturas africanas (quase sempre na língua do colonizador no espaço de língua portuguesa), levou ao surgimento de processos criativos não forçosamente demarcados dos contextos étnicos de produção.

A arte contemporânea africana usufrui hoje (ou começa a usufruir) de reconhecimento internacional, no que discordo ligeiramente de Feliciano de Mira (2019), um dos especialistas em arte contemporânea africana, nomeadamente na de Moçambique. Vários são os factos e acontecimentos que me levam a tal afirmação. A publicação, desde 1994, da prestigiada revista Nka Journal of Contemporary African Art, pela Duke University Press, talvez seja dos indicadores mais expressivos. Esta revista vem, no que respeita ao mercado mundial da arte, ombrear com a não menos prestigiada Oriental Art Magazine, que vem sendo publicada desde o fim da Segunda Guerra Mundial. O Art Africa Magazine, publicado na África do Sul, assim como muitas outras revistas e iniciativas, têm feito catapultar a criatividade africana contemporânea para os escaparates internacionais. Igualmente importante foi a fundação do Zeitz Museum of Contemporary Art Africa, na cidade do Cabo, dedicado à arte contemporânea africana. O papel do curador e crítico de arte Okwui Enwezor (1963-2019), de origem nigeriana, diretor da Haus der Kunst de Munique até junho de 2018, o primeiro curador africano a ser diretor da Bienal de Veneza, entre outros importantes cargos que desempenhou no universo mundial das artes, entre os quais o de coeditor do Nka Journal of Contemporary African Art, é outro indicador da visibilidade que a arte contemporânea africana tem vindo a conquistar. Várias são hoje, na verdade, as plataformas informáticas/empresas empenhadas na divulgação e internacionalização da arte contemporânea africana, com uma atuação global.

E essa afirmação passa igualmente pelo destaque que a ARCOLisboa 2019 deu à arte africana. Maribel Lopez, sua diretora, disse a propósito desse destaque, em entrevista conduzida por Celso Martins, que "o mundo da arte contemporânea, nos últimos anos, tem prestado mais atenção a África, observando a criação contemporânea no continente mais de perto" (Martins, 2019, p. 22) ${ }^{6}$.

Toda essa visibilidade é devida, em parte, à conjuntura atual, marcada pela globalização de economias, valores e gostos. O multiculturalismo como filosofia de vida vai-se

muitos outros artistas europeus também cometeram o mesmo engano, e com frequência” (p. 249).

6 A galeria luandense Jahmek foi galardoada, neste certame, ex aequo com a galeria londrina Copperfield, com o Prémio Opening, atribuído pela segunda vez às galerias que pertencem a essa categoria, isto é, galerias com menos de 7 anos de experiência. 
impondo paulatinamente, causando o que se poderá designar por democratização da estética e das instâncias de avaliação das obras de arte e, consequentemente, dos complexos processos de legitimação e consagração dos artistas.

A título conclusivo, vale referir que, perante a exiguidade e fragilidade dos mercados de arte periféricos, a cujo grupo pertence a generalidade dos mercados de arte africanos, incluindo o moçambicano, o turismo pode servir como um fator de dinamização; sobretudo quando os turistas procuram conhecer mais profundamente as sociedades e culturas visitadas. A arte contemporânea (e, de certa maneira, também o artesanato mais elaborado, não descaracterizado quanto às suas origens) poderá fornecer aos turistas internacionais vivências e recordações profundas da sua estadia e, simultaneamente, disponibilizar-lhes, com a obra de arte que compram, um meio de investimento seguro. Para tanto, devem ser implementadas políticas públicas reguladoras dos respetivos mercados de arte; medidas que assegurem, por um lado, a formação dos artistas, a sua profissionalização (o que passa pela criação de associações profissionais), a formação e existência de galeristas, a emergência de críticos de arte, a abertura e modernização de museus, e por aí adiante, e, por outro, a garantia de qualidade do que é produzido e vendido. A certificação da qualidade da obra de arte é, neste complexo em interação, imprescindível para o desenvolvimento de um fator importante na consolidação de um mercado de arte: a confiança. 0 mercado torna-se, assim, um fator de qualidade e não de desvalorização estética.

Bem, no caso de Moçambique, na verdade, há muito que a sua arte granjeou notoriedade fora de portas. Malangatana, cuja influência é passível de ser rastreada em muitos dos mais significativos pintores moçambicanos da atualidade, foi um exímio embaixador das artes plásticas moçambicanas. É seguramente um dos grandes nomes da arte contemporânea africana e da arte contemporânea em geral. É, como tal, um importante ativo na promoção do país como destino do turismo cultural.

Luís Polanah, pintor e antropólogo luso-moçambicano in memoriam

\section{Agradecimentos}

Este trabalho é financiado por fundos nacionais através da FCT - Fundação para a Ciência e a Tecnologia, I.P., no âmbito do projeto UIDB/00736/2020. É também apoiado no âmbito da "Knowledge for Development Initiative", pela Rede Aga Khan para o Desenvolvimento e pela FCT - Fundação para a Ciência e Tecnologia, IP (n. ${ }^{\circ}$ 333162622) no contexto do projeto Memories, cultures and identities: how the past weights on the present-day intercultural relations in Mozambique and Portugal? 


\section{Referências}

Chabal, P. (1994). Vozes moçambicanas. Literatura e nacionalidade. Vega.

Costa, A. (2013). Arte em Moçambique. Entre a construção da nação e o mundo sem fronteiras 1932-2004. Verbo.

Furtado, W. (2018). God's plan. C\& Platform for International Art from African Perspectives, 9, 44-46.

Galeano, E. (2009). Espelhos. Uma história quase universal. L\&PM Editores.

Leclerc, G. (1973). Crítica da antropologia. Ensaio acerca da história do africanismo (F. B. Pinheiro, Trad.). Editorial Estampa. (Trabalho original publicado em 1972)

Martins, C. (2019, 4 de maio). Maribel Lopez: "Uma feira está em constante estado de observação do mundo da arte". Expresso, 22-23.

Mbembe, A. (2014). Crítica da razão negra (M. Lança, Trad.). Antígona. (Trabalho original publicado em 2013)

Mira, F. de. (2019). Ao correr do olhar. Desafios para uma epistemologia poética. Almedina; Centro de Estudos Sociais.

Neves, J. M. (2013). Encontro com Dori e Pancho Guedes. Edições Afrontamento.

Nhulilivali, N. F. J. (2017). Inventário e análise sociológica das políticas públicas de turismo em Angola [Tese de doutoramento, Universidade de Évora]. Repositório Universidade de Évora. http://hdl.handle. net/10174/20674

Reckwitz, A. (2014). Die Erfindung der Kreativität. Zum Prozess gesellschaftlicher ästhetisierung. Suhrkamp Verlag.

Sindiga, I. (1999). Tourism and African development. Change and challenge of tourism in Kenya. Ashgate.

Sopa, A. (2017). Artes visuais em Moçambique - Um percurso de 100 anos. Estados de alma das artes em Moçambique. Artes plásticas, 11-20.

United Nations Conference on Trade and Development. (2017). Economic development in Africa. Tourism for transformative and inclusive growth. Report 17. Nações Unidas. https://unctad.org/system/files/ official-document/aldcafrica2017_en.pdf

Venâncio, J. C. (2009). 0 fato africano. Elementos para uma sociologia da África. Editora Massangana; Fundação Joaquim Nabuco.

Venâncio, J. C. (2014). A «África (eternamente) renascida»: Relendo três dos «seus» insignes pensadores: Léopold Sédar Senghor, Frantz Fanon e Amílcar Cabral. Vegueta: Anuario de la Facultad de Geografía y Historia, 14, 185-195. http://hdl.handle.net/1822/42358

Withers, T. (2017). Framing investment. Art Africa in conversation with Serge Tiroche. ART AFRICA, 10, $140-145$.

World Tourism Organization. (2019). World tourism barometer and statistical annex. January 2019. World Tourism Barometer, 17(1). https://doi.org/10.18111/wtobarometereng 